\title{
Budgetary participation and managerial performance: The impact of information and environmental volatility
}

\author{
Hasan Almasi ${ }^{\mathrm{a}}$, Mohammad Reza Palizdar ${ }^{\mathrm{b} *}$ and Hossein Parsian ${ }^{\mathrm{c}}$
}

${ }^{a}$ Assistant Professor of Management Department in Islamic Azad University, Central Tehran Branch of Iran

${ }^{b}$ Master of Science in Financial Management, Islamic Azad University

${ }^{c}$ Young Researchers and Elite Club, Torbat-e-Jam Branch, Islamic Azad University, Torbat-e-Jam, Iran

\section{H R O N I C L E}

Article history:

Received March 25, 2015

Received in revised format June

12015

Accepted June 272015

Available online

July 12015

Keywords:

Budgeting Participation

Managers' Performance

Resource Allocation

Job Satisfaction

Organizational Commitment

Organizational Trust

\begin{abstract}
A B S T R A C T
The present study investigates the effects of participation of managers in budgeting on their management performance in the Tehran regional electricity company. Variables of this study are participation in budgeting, performance of managers, adequacy of funding and resource allocation, job satisfaction, organizational commitment and organizational trust. The type of research is survey. The study population consists of all middle level managers of Tehran Regional Electricity Company who according to the approved organizational chart were 34 in 2012. The research tool is a questionnaire. Analysis of data collected is accomplished by using the SPSS and smartPLS. The results show a significant correlation between the variables of managers' participation in budgeting and organizational trust, adequacy of funding and resource allocation and job satisfaction, organizational trust of managers on organizational commitment, organizational commitment and competence in the absorption of funding and optimal resource allocation and finally the competence in funding and optimal resource allocation of managers as well as job satisfaction and management performance.
\end{abstract}

\section{Introduction}

The budget is the lifeline of any organization, because organizations do all their financial activities, including revenue and payment of expenses for the implementation of various programs in the framework of budget. Therefore, budget is the good reflection of all programs and activities of the organizations and plays essential role in national economic development (Hedayati, 2010). Budgeting is an important process because of its impact on the outputs. Budgeting associated with current affairs leads to improved management and performance of the program (Sayden, 2010). Foreign studies (Schick, 2007; Lee \& Wang, 2009) confirm the inappropriateness of traditional budgeting methods depending on the circumstances of the present time and show that these methods would not meet decision-makers' needs at various levels to manage the operations and programs.

\footnotetext{
* Corresponding author.

E-mail address: palizdarm@yahoo.com (M. R. Palizdar) 
Organizational Behavior Management (OBM) thinkers have stated a positive relationship between performance and participation in budgeting and achieving the organizational goals (Becker \& Green, 1962). Participation in budgeting facilitates the acquisition and the use of information associated with the job. Since participation in budgeting provides the management an opportunity to influence the budget before its finalization, so the manager has necessarily an active role and can participate more in the review and evaluation of different options for setting budget targets. Therefore, participation in budgeting increases management efforts to formulate predictions accurately because of environmental conditions and can lead to a focus of management on decisions and behaviors needed in future periods. It may also lead to increased thinking about the objectives of budget and different options (Early et al., 1987). Kern (1992) stated that participation in budgeting has led to an increase in information available to employees; this factor leads to increased managers' efficiency. He also stated that increasing the instability and volatility in the organization may have positive effects on corporate performance in budgeting increases (Kern, 1992). In fact, budget means planning and control and a budget that is prepared and regulated based on the studies, and the participation of managers of an institution determines the practice of management and provides desired harmony between the whole activity of a company or institute. However, since the budget is based on estimates, projections and possibilities, uncertainty of factors influencing on the budgeting system of the realization of revenues, right identifying the priorities and pressures of political and social leaders and influential social and political groups is not negligible. So the budget and its process is a combination of technical and political authorities and decisions which could lead to inconsistency in the administrative, economic, financial and legal systems, so using whichever method of budgeting is considered as one of the most complex and technical methods.

In this study, the issues associated with costs and revenues are reviewed due to its structural importance and to develop measurements to indicators of the performance of managers in a dynamic path to link between the issues and their origins. If budgeting which is considered as a tool for planning and controlling is accomplished by the participation of managers, it will undoubtedly lead to better and more effective performance. So the main question that arises in this research is to determine the type of relationship between participation of managers in budgeting and their management performance in Tehran regional electric company.

\section{Literature review}

Budgeting is the task of managers and budget is a tool to control, motivate and assess the performance. Many studies show that different levels of employees' involvement in budgeting improve the performance and achievement to organizational goals (Tavakkoli Mohammadi \& Etemadi, 2007).

Participation in budgeting: this variable is defined as the amount of involvement in the preparation and development of the budget (Tsui, 2001).

Performance: a set of actions and activities, which is accomplished by employees to achieve predetermined objectives of the organization and it is consisted of several indicators such as job satisfaction, commitment, ability, motivation, efficiency, etc. (Ang et al., 2007).

There are few studies about the effect of managers' participation in budgeting on their management performance in Tehran Regional Electricity Company. Zainuddin and Rahana (2011) studied the relationship between participation in budgeting and performance. The study aimed to investigate the relationship between participation in budgeting and management performance as well as the mediating role of the organizational justice and motivation in relationship between participation in budgeting and management performance. They provided a model of participatory budgeting which has the element of fairness and motivation. Mia (2010) studied the effect of participation in budgeting on management 
performance using a possible theories approach. Managerial attitude towards job and firm as well as motivation to work were studied in this survey. The results showed that both variables moderated the effect of participation in budgeting. In particular, participation in the budgeting process for managers who had more favorable attitudes or motivations were associated with improved performance, while the participation of managers who had bad attitude or motivation, was associated with different performance. Lopez et al. (2009) studied participation in budgeting and job performance of executives in South Korea and reported that the overall results, US executives and Asian managers, of research on participation in budgeting had no significant impact on their performance, but the participation in budgeting had a positive significant impact on managers' job performance indirectly through job satisfaction. Eker (2009) examined the relationship between participation in budgeting and job-related information on managerial performance and the results showed that subjects with high performance tend more than subjects with low performance to apply the participation in budgeting and job-related information. However, the study showed that the duration of the mutual interaction was important and thus higher interaction between budget participation and job-related information was associated with higher management performance. Yuen (2007) reviewed the background of participation in activities related to the budget, the need to feel success and positive attitude to work and then determination of the effects of these two variables on the job performance in the public sector organizations. He reported that the two factors of positive attitude to work and need for success had a significant positive correlation with participation in budgeting. In addition, indirect relationship existed between two variables of attitude to work and need for success and job performance with participation in budgeting as an intervening variable. Izzetin (1997) examined some of the features of the general goal related to budgeting including participation, transparency, feedback, assessment and various forms of attitudes to work in terms of job satisfaction, job involvement, job stress as well as budget related attitudes in terms of attitudes towards the budget, budget motivation and the self-performance assessment including budget performance, cost efficiency, job performance of managers in industrial units who had the responsibility for the budget and the results. In this survey, budget related participation and transparency of the budget target had significant positive effects on attitudes related to the job and to budgets of managers.

According to Frucot and Shearon (1991), previous researches suggest internal-external source of individual control was effective on participation in the budgeting process and job satisfaction and performance of managers and the results also showed that the effect of control source on management satisfaction was not significant and the lack of significance on management satisfaction reflects the visible difference in culture. Hosseini (2010) examined the direct and indirect effects of participation in budgeting on the state enterprise managers' performance. The results showed that increasing the participation of managers of state owned enterprises either directly or indirectly improves the performance of managers in those companies. Culture is also indirectly effective on the relationship between the participation in budgeting and performance of public managers. Kren (1992) examined the perceived level of job-relevant information (JRI) as an intervening variable between budgetary participation and individual performance. JRI is information, which could facilitate job-related decision making. He reported that participation affects performance, not directly, but through JRI. Moreover, this positive performance effect of participation persisted and was more pronounced when environmental volatility was high, although the results did not provide unambiguous evidence.

Etemadi and Dianati Deilami (2008), by studying the effects of organizational culture, participation in budgeting and accounting systems of management on management performance concluded that in high power distance and collectivist societies or organizations, participation of people in budgeting, even with proper management accounting data would not necessarily lead to the success of the management performance. But a positive relationship could exist between management accounting systems and performance in individualist organizations with low power distance. The results obtained confirm the relationship between participation in budgeting, management accounting systems and management 
performance and the effectiveness of organizational culture on this type of relationship. Tavakoli Mohammadi and Etemadi (2007) investigated the relationship between the participation of staff in budgeting and managers' performance and effects of job-related information on the relationship in the main companies affiliated with the Ministry of Oil in Iran. Results showed that participation in budgeting had a significant role in the management access to job-related information and improves their performance. Shirvani (1998) indicated that a significant correlation could exist between the participation in budgeting and job-related information and between the job-related information and the manager performance. Participation in budgeting was directly associated with the job-related information and also job-related information had a direct relationship with the manager performance and claimed that the higher the participation in budgeting, his business information increases and the information improves his performance.

\section{Conceptual model of research}

Conceptual model of the present study is the result of the study of theoretical principles of research and identification of existing models in research area including Sugioko's model (2010) where the dimensions and indicators of the effect of managers' participation in budgeting on their management performance were extracted.

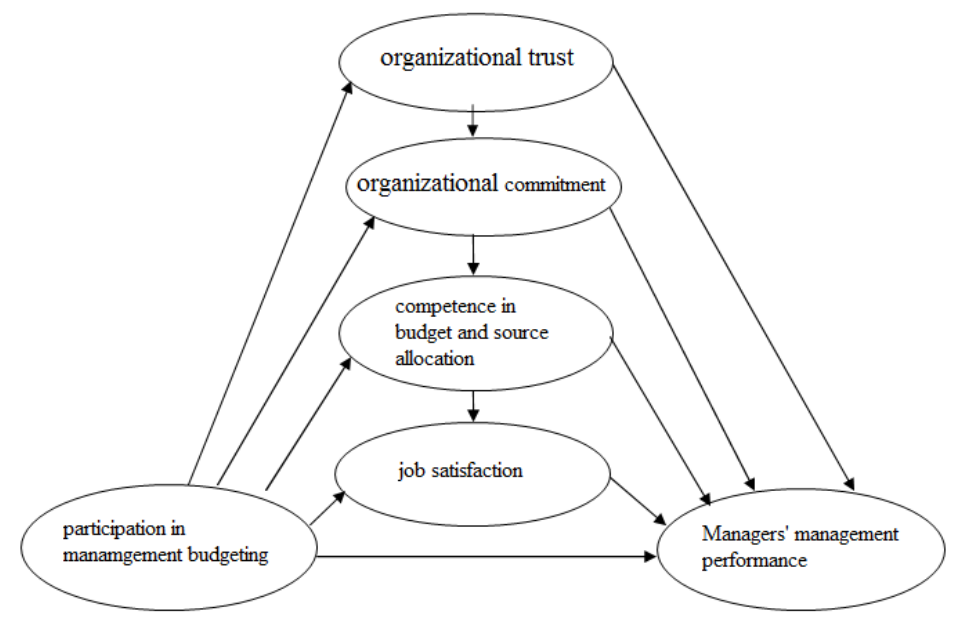

Fig. 1. Conceptual model of research adopted from Sugioko model (2010)

The research is applied according to the classification based on objective and a descriptive - survey in terms of method. The study statistical population consisted of all middle level managers of Tehran Regional Electricity Company who were 34 subjects and because of the limited statistical sample, the researcher decided to consider the entire population as sample. The most important methods of collecting data in this study are as follows:

1. Desk study: in this area, library sources, articles, books required, the Global Information Network (Internet) has been used to collect data on the theoretical basics and research literature.

2. Field research: in field research, to collect data, the researcher has to go out and communicate with people and organizations. He needs to bring out the assessment tool or data and complete them with questionnaire, interview, observation and imaging. The tool used to collect data in this study consisted of a questionnaire. In this study, to ensure the content validity of the questionnaire, the questionnaire was provided for the supervisors and advisors and also a number of experts to express their ideas about the variables and the identified indices; after review by the experts, it was decided to use the inventory with changes (according to the study organization). Finally, by applying desired changes, the validity of the questionnaire was confirmed by these people. After validation, questionnaires were distributed among managers and were collected. Also the questionnaire reliability was calculated using Cronbach alpha 
formula that the mean Cronbach's alpha obtained of total questionnaire was 0.839. Given that the amount is more than 0.7 , the reliability of the questionnaire was confirmed. In this study, the statistical analysis was descriptive and inferential analysis and SPSS and SmartPLS were used for data analysis.

\subsection{Research questions}

1. A significant relationship exists between participation of managers in budgeting and their management performance in Tehran Regional Electricity Company.

2. A significant relationship exists between participation of managers in budgeting and their organizational trust in Tehran Regional Electricity Company.

3. A significant relationship exists between the organizational trust of managers and their managerial performance in Tehran Regional Electricity Company.

4. A significant relationship exists between the organizational trust and their organizational commitment in Tehran Regional Electricity Company.

5. A significant relationship exists between participation of managers in budgeting and their organizational commitment in Tehran Regional Electricity Company.

6. A significant relationship exists between managers' organizational commitment and their managerial performance in Tehran Regional Electricity Company.

7. A significant relationship exists between managers' organizational commitment and their competence in attracting funding and resource allocation in Tehran Regional Electricity firm.

8. A significant relationship exists between managers' participation in budgeting and their competence in funding and resource allocation in Tehran Regional Electricity Company.

9. A significant relationship exists between competence in funding and resource allocation of managers and their job satisfaction in Tehran Regional Electricity Company.

10. A significant relationship exists between the competence in funding and resource allocation of managers and their performance management in Tehran Regional Electricity Company.

11. A significant relationship exists between participation of managers in budgeting and their job satisfaction in Tehran Regional Electricity Company.

12. A significant relationship exists between job satisfaction of managers and their managerial performance in Tehran Regional Electricity Company.

\section{Analysis of results and findings}

In our survey, $82.4 \%$ of the participants were male and $17.6 \%$ of them were female. Fig. 2 presents other personal characteristics of the participants.

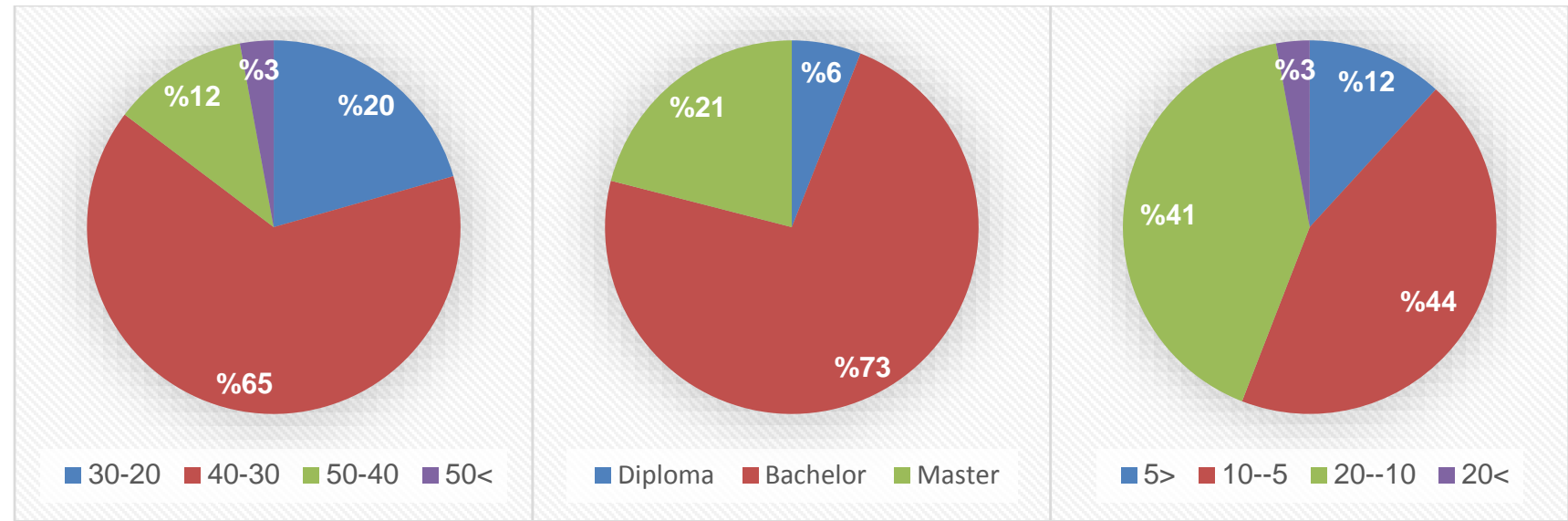

Age
Expertise
Education

Fig. 2. Personal characteristics of the participants 
As we can observe from the results of Fig. 1, most participants were middle aged with good university educations and job experiences. Kolmogorov-Smirnov test indicates that the variables were normally distributed. Table 1 demonstrates the results of testing different hypotheses.

\section{Table 1}

The summary of testing various hypotheses

\begin{tabular}{|c|c|c|c|c|}
\hline Relationship of concepts with the parameters in model & Path coefficient & T-value & Sig. & Result \\
\hline $\begin{array}{l}\text { A significant relationship exists between participation of managers in budgeting and } \\
\text { their management performance in Tehran Regional Electricity Company. }\end{array}$ & -0.319 & 0.966 & $\mathrm{P}>0.05$ & Rejected \\
\hline $\begin{array}{l}\text { A significant relationship exists between participation of managers in budgeting and } \\
\text { their organizational trust in Tehran Regional Electricity Company. }\end{array}$ & 0.618 & 10.29 & $\mathrm{P}<0.01$ & Confirmed \\
\hline $\begin{array}{l}\text { A significant relationship exists between the organizational trust of managers and } \\
\text { their managerial performance in Tehran Regional Electricity Company. }\end{array}$ & 0.923 & 2.015 & $\mathrm{P}<0.01$ & Confirmed \\
\hline $\begin{array}{l}\text { A significant relationship exists between the organizational trust and their } \\
\text { organizational commitment in Tehran Regional Electricity Company. }\end{array}$ & 0.781 & 12.62 & $\mathrm{P}<0.01$ & Confirmed \\
\hline $\begin{array}{l}\text { A significant relationship exists between participation of managers in budgeting and } \\
\text { their organizational commitment in Tehran Regional Electricity Company. }\end{array}$ & -0.043 & 0.463 & $\mathrm{P}>0.05$ & rejected \\
\hline $\begin{array}{l}\text { A significant relationship exists between managers' organizational commitment and } \\
\text { their managerial performance in Tehran Regional Electricity Company. }\end{array}$ & -0.763 & 1.632 & $\mathrm{P}>0.05$ & Rejected \\
\hline $\begin{array}{l}\text { A significant relationship exists between managers' organizational commitment and } \\
\text { their competence in attracting funding and resource allocation in Tehran Regional } \\
\text { Electricity Company. }\end{array}$ & 0.532 & 7.965 & $\mathrm{P}<0.01$ & Confirmed \\
\hline $\begin{array}{l}\text { A significant relationship exists between managers' participation in budgeting and } \\
\text { their competence in funding and resource allocation in Tehran Regional Electricity } \\
\text { Company. }\end{array}$ & 0.414 & 5.534 & $\mathrm{P}<0.01$ & Confirmed \\
\hline $\begin{array}{l}\text { A significant relationship exists between competence in funding and resource } \\
\text { allocation of managers and their job satisfaction in Tehran Regional Electricity } \\
\text { Company. }\end{array}$ & 0.731 & 10.092 & $\mathrm{P}<0.01$ & Confirmed \\
\hline $\begin{array}{l}\text { A significant relationship exists between the competence in funding and resource } \\
\text { allocation of managers and their performance management in Tehran Regional } \\
\text { Electricity Company. }\end{array}$ & 0.725 & 1.566 & $\mathrm{P}>0.05$ & Rejected \\
\hline $\begin{array}{l}\text { A significant relationship exists between participation of managers in budgeting and } \\
\text { their job satisfaction in Tehran Regional Electricity Company. }\end{array}$ & 0.164 & 1.862 & $\mathrm{P}>0.05$ & Rejected \\
\hline $\begin{array}{l}\text { A significant relationship exists between job satisfaction of managers and their } \\
\text { managerial performance in Tehran Regional Electricity Company. }\end{array}$ & -0.575 & 1.211 & $\mathrm{P}>0.05$ & Rejected \\
\hline
\end{tabular}

Path coefficient shows the relationships between variables and the range of the coefficient is between -1 to 1 . When the ration tends to 1 it reflects more strength of the relationship between the variables. In addition, t-student shows the significance of factor loading estimate (significant difference of factor loading with zero). Values of $\mathrm{T}$ between -1.96 and 1.96 indicate the absence of a significant effect between latent variables. Any t-value between 1.96 and 2.576 represents the significance effect with more than $95 \%$ confidence among the latent variables. T-values equal or greater than 3.29 indicate the significance effect with more than $99 \%$ confidence among the latent variables. Thus, as observed in Table 1, the impact of variables on each other is confirmed with over $99 \%$ confidence.

\section{Table 2}

Model fitting parameters

\begin{tabular}{|c|c|c|c|c|}
\hline Variable & CR & AVE & R-Square & Cronbach alpha \\
\hline Participation in budgeting & 0.8283 & 0.4493 & 0.0000 & 0.7503 \\
\hline Management performance & 0.1708 & 0.2234 & 0.3843 & 0.4312 \\
\hline $\begin{array}{l}\text { Competence in funding and } \\
\text { resource allocation }\end{array}$ & 0.8618 & 0.4719 & 0.6483 & 0.8133 \\
\hline Job satisfaction & 0.9244 & 0.2839 & 0.7166 & 0.9166 \\
\hline Organizational commitment & 0.8349 & 0.2805 & 0.57 & 0.8061 \\
\hline Organizational trust & 0.7873 & 0.3705 & 0.3822 & 0.7164 \\
\hline
\end{tabular}

The method of estimation in PLS is non-parametric. Hence, the parameters obtained in the PLS all show the fit quality. This means that the parameters are between 0 and 1 . The parameters are called 
absolute and relative respectively (a criteria for closeness of estimated values of the dependent variable through fitted model compared to the original data) and also external model (measurement of variables through factor analysis and construct validity) and internal model (fitting the structural model). As can be seen in Table 2, all Criteria represent the quality fitness of the model. According to Table 2, for the composite reliability index, it is observed that it is more than 0.7 for most of the variables which indicates their favorability. Reported values for R-Square are acceptable for the research variables. The Cronbach alpha coefficients are also appropriate for most of variables and they are above 0.7. So all the used parameters of fitting show that this model has an acceptable fit. Therefore, we conclude that the research model has a great potential in measuring the main variables.

\subsection{Testing the research hypotheses}

First hypothesis: A significant relationship exists between participation of managers in budgeting and their management performance in Tehran Regional Electricity Company.

The PLS analysis shows that the participation of managers in budgeting improved their management performance significantly with more than $95 \%$ confidence $\left(\mathrm{P}<0.01, \mathrm{~T}=0.966, \mathrm{PC}^{1}=-0.319\right)$, therefore $\mathrm{H}_{1}$ is rejected and $\mathrm{H}_{0}$ is accepted. Findings of the hypothesis are not consistent with the researches by Lopez et al. (2009), Latch Lopez et al. (2009), Yuen (2007), Hosseini (2010) and Tavakkoli Mohammadi and Etemadi (2007).

Second hypothesis: A significant relationship exists between participation of managers in budgeting and their organizational trust in Tehran Regional Electricity Company.

According to the results, the participation of managers in budgeting improved their organizational trust significantly with more than 95\% confidence ( $\mathrm{PC}=0.618, \mathrm{P}<0.01, \mathrm{~T}=10.29$ ), therefore $\mathrm{H}_{0}$ is rejected and $\mathrm{H}_{1}$ is accepted. The finding of the hypothesis is consistent with the researches by Lopez et al. (2009), Latch Lopez et al. (2009), Yuen (2007), Hosseini (2010) and Tavakkoli Mohammadi and Etemadi (2007).

Third hypothesis: A significant relationship exists between the organizational trust of managers and their managerial performance in Tehran Regional Electricity Company.

According to the results, the managers' organizational trust improved their managerial performance significantly with more than 95\% confidence ( $\mathrm{PC}=0.923, \mathrm{P}<0.01, \mathrm{~T}=2.015$ ), therefore $\mathrm{H}_{0}$ is rejected and $\mathrm{H}_{1}$ is accepted. The finding of the hypothesis is consistent with the researches by Lopez et al. (2009), Latch Lopez et al. (2009), Yuen (2007), Hosseini (2010), and Tavakkoli Mohammadi and Etemadi (2007).

Fourth hypothesis: A significant relationship exists between the organizational trust and their organizational commitment in Tehran Regional Electricity Company.

The results show that the managers' organizational trust improved their organizational commitment significantly with more than 95\% confidence ( $\mathrm{PC}=0.781, \mathrm{P}<0.01, \mathrm{~T}=12.62$ ), therefore $\mathrm{H}_{0}$ is rejected and $\mathrm{H}_{1}$ is accepted. The finding of the hypothesis is consistent with the researches by Lopez et al. (2009), Yuen (2007), Hosseini (2010) and Tavakkoli Mohammadi and Etemadi (2007).

Fifth hypothesis: A significant relationship exists between participation of managers in budgeting and their organizational commitment in Tehran Regional Electricity Company.

\footnotetext{
${ }^{1}$ Path coefficient
} 
The results show that the participation of managers in budgeting improved their organizational commitment significantly with more than $95 \%$ confidence ( $\mathrm{PC}=-0.043, \mathrm{P}<0.01, \mathrm{~T}=0.463$ ), therefore $\mathrm{H}_{1}$ is rejected and $\mathrm{H}_{0}$ is accepted. Findings of the hypothesis are not consistent with the researches by Lopez et al. (2009), Latch Lopez et al. (2009), Yuen (2007), Hosseini (2010) and Tavakkoli Mohammadi and Etemadi (2007).

Sixth hypothesis: A significant relationship exists between managers' organizational commitment and their managerial performance in Tehran Regional Electricity Company.

The results show that the organizational commitment did not improve their management performance significantly with more than $95 \%$ confidence $\left(\mathrm{PC}=-0.763, \mathrm{P}>0.05, \mathrm{~T}=1.632\right.$ ), therefore $\mathrm{H}_{1}$ is rejected and $\mathrm{H}_{0}$ is accepted. Findings of the hypothesis are not consistent with the researches by Lopez et al. (2009), Yuen (2007), Hosseini (2010) and Tavakkoli Mohammadi and Etemadi (2007).

Seventh hypothesis: A significant relationship exists between managers' organizational commitment and their competence in attracting funding and resource allocation in Tehran Regional Electricity Company.

The analyses show that the organizational commitment of managers improved the competence in funding and resource allocation significantly with more than $95 \%$ confidence $(\mathrm{PC}=0.532, \mathrm{P}<0.01$, $\mathrm{T}=7.965$ ), therefore $\mathrm{H}_{0}$ is rejected and $\mathrm{H}_{1}$ is accepted. Findings of the hypothesis are consistent with the researches by Lopez et al. (2009), Latch Lopez et al. (2009), Yuen (2007), Hosseini (2010) and Tavakkoli Mohammadi and Etemadi (2007).

Eighth hypothesis: A significant relationship exists between managers' participation in budgeting and their competence in funding and resource allocation in Tehran Regional Electricity Company.

The results show that the participation of managers in budgeting improved the competence in budgeting and resource allocation significantly with more than 95\% confidence $(\mathrm{P}<0.01, \mathrm{~T}=5.534, \mathrm{PC}=0.414)$, therefore $\mathrm{H}_{0}$ is rejected and $\mathrm{H}_{1}$ is accepted. The findings of the hypothesis are consistent with the researches by Lopez et al. (2009), Latch Lopez et al. (2009), Yuen (2007), Hosseini (2010) and Tavakkoli Mohammadi and Etemadi (2007).

Ninth hypothesis: A significant relationship exists between competence in funding and resource allocation of managers and their job satisfaction in Tehran Regional Electricity Company.

The PLS analyses show that the competence in funding and resources allocation of managers improved their job satisfaction significantly with more than 95\% confidence ( $T=10.092, \mathrm{P}<0.01, \mathrm{PC}=0.731$ ), therefore $\mathrm{H}_{0}$ is rejected and $\mathrm{H}_{1}$ is accepted. The findings of the hypothesis are consistent with the researches by Lopez et al. (2009), Latch Lopez et al. (2009), Yuen (2007), Hosseini (2010) and Tavakkoli Mohammadi and Etemadi (2007).

Tenth Hypothesis: A significant relationship exists between the competence in funding and resource allocation of managers and their performance management in Tehran Regional Electricity Company.

The results of the survey show that the competence in funding and resources allocation of managers did not improve their management performance significantly with more than $95 \%$ confidence $(\mathrm{P}>0.05$, $\mathrm{T}=1.566$, $\mathrm{PC}=0.572$ ), therefore $\mathrm{H}_{1}$ is rejected and $\mathrm{H}_{0}$ is accepted. The findings of the hypothesis are not consistent with the researches by Lopez et al. (2009), Latch Lopez et al. (2009), Yuen (2007), Hosseini (2010) and Tavakkoli Mohammadi and Etemadi (2007). 
Eleventh hypothesis: A significant relationship exists between participation of managers in budgeting and their job satisfaction in Tehran Regional Electricity Company.

In our survey, the participation of managers in budgeting did not improve their job satisfaction significantly with more than $95 \%$ confidence $(\mathrm{PC}=0.164, \mathrm{P}>0.05, \mathrm{~T}=1.862)$, therefore $\mathrm{H}_{1}$ is rejected and $\mathrm{H}_{0}$ is accepted. The findings of the hypothesis are not consistent with the researches by Lopez et al. (2009), Latch Lopez et al. (2009), Yuen (2007), Hosseini (2010) and Tavakkoli Mohammadi and Etemadi (2007).

Twelfth hypothesis: A significant relationship exists between job satisfaction of managers and their managerial performance in Tehran Regional Electricity Company.

The results of PLS analyses show that the managers' job satisfaction did not improve their management performance significantly with more than $95 \%$ confidence ( $\mathrm{PC}=-0.575, \mathrm{P}>0.05, \mathrm{~T}=1.211$ ), therefore $\mathrm{H}_{1}$ is rejected and $\mathrm{H}_{0}$ is accepted. Findings of the hypothesis are not consistent with the researches by Lopez et al. (2009), Latch Lopez et al. (2009), Yuen (2007), Hosseini (2010) and Tavakkoli Mohammadi and Etemadi (2007).

\section{Conclusion and recommendations}

The present study has investigated the effects of managers' participation in budgeting on their management performance in Tehran Regional Electricity Company. The results have showed that a significant relationship existed between the variables of managers' participation in budgeting and organizational trust, competence in funding and resource allocation and job satisfaction, organizational commitment on organizational trust, organizational commitment of managers and competence in funding and resource allocation and finally the variable of competence in funding and resource allocation of managers and job satisfaction and management performance. According to the findings of the present study, the following recommendations are offered:

Recommendations with regard to the first research hypothesis: Regarding the impact of the components of managers' participation in budgeting on management performance, it is recommended to improve the indicators of the participation rate in the formulation of the budget, the rationality of offered arguments by the top managers about the proposed budget amendment, submitting requests, comments and recommendations to superiors, without the need for them, effectiveness of person in the final budget, having a share for managers to regulate the budget and finally searching suggestions, idea and demands of managers by their superiors to improve the participation of managers in the budgeting.

Recommendations with respect to the second hypothesis: According to impacts of managers' participation in the budgeting on organizational trust, it is recommended to improve the criteria of having confidence in the honesty of organization to the person, expecting the organization to have a stable and predictable behavior for a person, the rate of integrity and honesty in all circumstances, high levels of the organization's expectations and positive intentions regarding the employees, fairness of organization towards employees, transparency and honesty of organization about the staff and finally the high level of trust of managers in the organization to improve the participation of managers in the budgeting.

Recommendations with respect to the third research hypothesis: Regarding the impact of organizational trust of managers and management performance, it is recommended to improve the criteria of planning, coordination and evaluation, coordination, evaluation, administration, recruitment and organization of human resources, negotiation and representation to improve the participation of managers in budgeting. 
Recommendations regarding the fourth research hypothesis: Regarding the impact of organizational trust of managers and organizational commitment, it is recommended to improve the criteria of being satisfied with the work in organization, knowing the problems of organization as one's problems, having a sense of "dependency" about the organization, having "emotional attachment" to the organization, knowing oneself as part of the family of organization, having a great personal value to the organization, having a commitment to continue working in the organization, not belonging solely to the benefits of the organization, having a guilty conscience to leave the organization, deserving the organization to be faithful to, having a sense of mutual commitment between the organization and the individual and the individual's desire to remain in work to improve the organizational trust in managers.

Recommendations regarding the fifth research hypothesis: Regarding the impact of managers' participation in budgeting and organizational commitment, it is recommended to improve the parameters of participation in the process of drafting the budget, the rationality of arguments offered by the top managers on the proposed budget amendment, submitting requests, comments and suggestions to superiors, without declaring the need for them, the effectiveness of person at the final budget, having a share for managers to regulate the budget and ultimately searching for managers' comments, suggestions and demands by their superiors to improve the organizational trust of managers.

Recommendations regarding the sixth research hypotheses: Regarding the impact of organizational commitment of managers and management performance, it is recommended to improve criteria of planning, coordination and evaluation, coordination, evaluation, administration, recruitment and organization of human resources, negotiation and representation to improve the organizational trust in managers.

Recommendations regarding the seventh research hypothesis: Regarding the impact of organizational commitment of managers and competence in funding and resource allocation it is recommended to improve the indicators of having non-economic information such as employee and customer satisfaction and products quality, high ability of data collected for different and understandable formulations, favorable reflection of reports of variable and fixed costs, the ability to report summarized, comparative and trend data in regular intervals, the ability to report summarized and useful information on the role and impact of activities of different sectors of organizations, determining precise targets for the activities performed and the cost of the individual and ultimately the individual's level of access to information of capacity, cost, sale price and size of production in different units to improve the organizational trust in managers.

Recommendations regarding the eighth research hypotheses: Regarding the impact of managers' participation in budgeting and resource allocation, it is recommended to improve the indicators of being satisfied with working in the organization, knowing the problems of organization as one's problems, having a sense of high "dependency", to organization, having a sense of "emotional attachment" to the organization, knowing oneself as a member of the organization, having a great personal value of the organization to the individual, having a sense of commitment to continue working in the organization, not belonging to the benefits of organizations, having a sense of guilty conscience in case of leaving the organization, deserving the organization to enjoy the person being faithful to it, having a sense of mutual commitment between the organization and the individual and the individual's desire to remain in organization to improve the organizational trust in managers.

Recommendations regarding the ninth research hypothesis: Regarding the impact of competence in funding and resource allocation of managers and job satisfaction, it is recommended to improve the indices of job satisfaction, knowing oneself responsible to the organization, considering the job as interesting, appreciating the individual in the organization, satisfying promotion of individual, equal 
opportunities of promotion for all individuals, motivating work tasks for the individual, having intimate relationships for individual and having a sense of security for individual improve the job satisfaction of managers.

Recommendations regarding the tenth hypothesis: Regarding the impact of competence in funding and resource allocation of management and management performance, it is recommended to improve indicators of having non-financial information, such as employee and customer satisfaction and product quality and high ability of data collected for various understandable formulations, favorable reflection of reports on variable and fixed costs, the ability to report summarized, comparative information and trends in regular intervals, the rate of ability to report summarized and useful information on the role and impact of activities of various sectors of the organization, determining precise objectives for the activities and expenditures made and finally the amount of individual access to capacity information, cost, sale price and volume of production of various units to improve the job satisfaction in managers.

Recommendations regarding the eleventh research hypothesis: Regarding the impact of managers' participation in budgeting and their job satisfaction, it is recommended to improve the indicators of participation in regulating budget, rationality of arguments offered by top managers on proposed budget amendment, submitting requests, comments and suggestions to superiors, without declaring the need to them, effectiveness of person in the final budget, having a share for managers for regulating budget and finally searching for managers comments, suggestions and demands by their superiors, attempted to improve these components contribute to improving the management to improve the managers' participation in the budgeting.

Recommendations regarding the twelfth research hypothesis: Regarding the impact of managers' job satisfaction and management performance, it is recommended to improve the indicator of planning, coordination and evaluation, coordination, evaluation, administration, recruitment and organization of human resources, negotiation and representation to improve the participation of managers in budgeting.

Due to limited research executed on investigating the impact of managers' participation in budgeting on their management performance, it is recommended to expand the size and the indicators of the model by using the viewpoints of experts and examine other variables affecting the performance of managers as mediating variable in another research.

\section{References}

Ang, S., Van Dyne, L., Koh, C., Ng, K. Y., Templer, K. J., Tay, C., \& Chandrasekar, N. A. (2007). Cultural intelligence: Its measurement and effects on cultural judgment and decision making, cultural adaptation and task performance. Management and organization review, 3(3), 335-371.

Becker, S., \& Green, D. (1962). Budgeting and employee behavior. Journal of Business, 35(4), 392402.

Caiden, N. (2010). Challenges confronting contemporary public budgeting: retrospectives/prospectives from Allen Schick. Public Administration Review,70(2), 203-210.

Earley, P. C., Wojnaroski, P., \& Prest, W. (1987). Task planning and energy expended: Exploration of how goals influence performance. Journal of applied psychology, 72(1), 107.

Bilgi, B. K. V. İ. İ., \& İșkinin, A. (2008). The effect of the relationship between budget participation and job-relevant information on managerial performance. Academic Review, 8(1), 183-198.

Etemadi, H., \& and Dianati Deilami, Z. (2008). Effects of organizational culture, participation in budgeting and accounting systems of management on management performance. Management Studies in Iran, 13(4), 60-35. 
Eker, M. (2009). The impact of budget participation and management accounting systems on performance of Turkish middle level managers. Akdeniz University Faculty of Economics \& Administrative Sciences Faculty Journal/Akdeniz Universitesi Iktisadi ve Idari Bilimler Fakultesi Dergisi, 9(17).

Frucot, V., \& Shearon, W. T. (1991). Budgetary participation, locus of control, and Mexican managerial performance and job satisfaction. Accounting Review, 66(1), 80-99.

Hedayati, A. (2010). Costing in the operational budgeting. Proceedings of the 4th International Conference on Operational Budget; Tehran, the Accounting Review, pp. 80-.99.

Hosseini, S.J. (2010). Direct and indirect effects of participation in the budgeting on the performance of the state enterprise managers. Master's thesis.

Kenis, I. (1979). Effects of budgetary goal characteristics on managerial attitudes and performance. Accounting Review, 54(4), 707-721.

Kren, L. (1992). Budgetary participation and managerial performance: The impact of information and environmental volatility. Accounting Review, 67(3), 511-526.

Leach-López, M. A., Stammerjohan, W. W., \& Sang Lee, K. (2009). Budget participation and job performance of South Korean managers mediated by job satisfaction and job relevant information. Management Research News, 32(3), 220-238.

Lee, J. Y. J., \& Wang, X. (2009). Assessing the Impact of Performance-Based Budgeting: A Comparative Analysis across the United States, Taiwan, and China. Public Administration Review, 69(s1), S60-S66.

Mia, L. (1988). Managerial attitude, motivation and the effectiveness of budget participation. Accounting, Organizations and Society, 13(5), 465-475.

Schick, A. (2007). Performance Budgeting and Accrual Budgeting. OECD Journal on Budgeting, 7(2), 109-138.

Shirvani, M.A. (1998). Effect of participation in budgeting on performance of managers in Iran's oil industry. Master's thesis.

Sugioko, S. (2010). The Impact of budget participation on job performance of university executives: A study of APTIK-Member Universities in Indonesia. Kasetsart Journal, 31, 271-279.

Tavakkoli Mohammadi, M., \& Etemadi, H. (2007). The relationship between participation in budgeting and performance of managers and the effect of job-related information in the main companies affiliated with the Ministry of Petroleum. Daneshvar Scientific Research Bimonthly, Shahed University, 16(23).

Tsui, J. S. (2001). The impact of culture on the relationship between budgetary participation, management accounting systems, and managerial performance: an analysis of Chinese and Western managers. The international journal of accounting, 36(2), 125-146.

Yuen, D. (2007). Antecedents of budgetary participation: enhancing employees' job performance. Managerial Auditing Journal, 22(5), 533-548.

Zainuddin, S., \& Isa, C. R. (2011). The role of organizational fairness and motivation in the relationship between budget participation and managerial performance: A conceptual paper. Australian Journal of Basic and Apllied Sciences, 5(12), 641-648. 